she believes this to be "the cross she must bear" and that it will resolve itself after she has had a child. That this myth should still persist is of little comfort to the young girl or, indeed, any woman. Childbirth itself is no permanent cure for spasmodic dysmenorrhoea, since the pain in the menstrual cycle is associated with the ovulatory cycle, which, of course, in normal circumstances, recommences after childbirth.

Conventional treatment ranges from analgesics to oral contraceptives, and, while varying degrees of relief are obtained, each form of treatment has its own drawbacks. Analgesics of the aspirin and codeine variety produce symptoms of gastritis, replacing the pain from spasmodic dysmenorrhoea with epigastric pain. Oral contraceptives have their place, but prescribing these for the very young girl is fraught with ethical difficulties.

Over a period of 15 years I treated about 60 women suffering from spasmodic dys menorrhoea with cyclandelate and obtained consistently good results in relieving the pain. With $800 \mathrm{mg}$ daily in divided doses for three days before the expected start of menstruation and for the first two days of the period itself the relief from pain was complete in many cases. Unfortumately, as often happens in clinical practice, one gains a strong subjective clinical impression which is later reinforced by similar clinical results, and consideration of objective measurements is not made until the therapeutic benefits in a number of patients are obvious. Thus, my experience with cyclandelate is based on my own subjective clinical impressions over period of time. During the 15 years that I have prescribed cyclandelate I have not seen any evidence of side effects or teratogenicity.

I should be interested to learn if any of your readers have had any similar experience with this drug.-I am, etc.

Buckhurst Hill,

DOROTHEA KERSLAKE

Essex

SIR,-With reference to your leading article (12 May, p. 323), having had first-hand experience of all the ills described in various degrees I can heartily endorse the views of the Drs. K. J. and R. J. Lennane. ${ }^{1}$ However, I must defend the psychoprophylaxis of pain in labour as it is taught today. Though derived from the theories of Grantly DickRead, it is modified. Mothers are taught to expect pain, but by positive methods using sensory dissociation, physiological breathing patterns, and relaxation of voluntary muscle pain is minimized and labour is allowed to proceed at maximum efficiency. From this it follows that labour is shorter, little or no analgesia is needed, and therefore morbidity is kept to the absolute minimum. Recovery of both mother and baby is quicker, and a stronger link is forged between the two. Most mothers can look back on labour as a tremendously worth-while and satisfying experience. I can count myself among them.

Some obstetric units, though not officially teaching the method, are sympathetic to mothers using it and I believe are often quite surprised at the results. Far from meeting a "punitive attitude," many mothers have analgesia thrust upon them and have to make most emphatic denials. It is not appreciated that analgesia can so cloud the consciousness that the method can no longer work.
Unfortunately, there is still a great deal the latter requires handloading and the deof prejudice against psychoprophylaxis, prob- gree of copper absorption is unknown. The ably for precisely the same reasons as put $25 \mathrm{~S}$ device, on the other hand, does not forward in your article-namely, that doctors seem to have any significant disadvantages tend to be too authoritarian and, being predominantly male, can never really understand those common disorders affecting women and their offspring.-I am, etc.,

Prunella E. Newton

Sale, Cheshire

E. NEWTON

1 Lennane, K. J., and Lennane, R. J., New England foumal of Medicine, 1973, 288, 288.

\section{A New I.U.C.D. for Nulliparous Patients}

SIR,-Your timely leading article (7 April, p. 2) reminds us that intrauterine devices are a valuable means of contraception and that nulliparous patients need not be denied this protection. I would like to report early experience with a new plastic I.U.C.D., similar to the $33 \mathrm{~S}$ and $32 \mathrm{~S}$ Saf-T-Coils, but redesigned to suit the nulliparous uterus. This is the $25 \mathrm{~S}$ device which is compared with the Gravigard Copper 7 (left) and small Dalkon shield (right) in the accompanying figure.

A pilot study in unselected patients was started in July 1972. Forty insertions have now been made with follow-up for between five and 10 months. Twenty-two patients were nulliparous, seven had previously born children or had miscarried, and 11 had been aborted. Seventeen patients were single. Ages ranged between 20 and 34 years. Insertions were particularly simple using a special flexible intrauterine sound without tenaculum forceps. Neither cervical dilatation nor local anaesthesia was necessary. The device was fitted after diagnostic dilatation and curettage in one case and following pregnancy termination in four others. Postinsertion discomfort occurred in six patients but resolved with analgesics.

Gonococcal salpingitis was diagnosed in one case, a beta-haemolytic (group A) streptococcal vaginal infection was found in another, and four patients had non-specific vaginitis. All responded to treatment without removal of the device. Conjugated equine oestrogens were used effectively in two patients who developed moderate menorrhagia but in other patients menstruation was not adversely affected. No pregnancy occurred in this series. One device was expelled after five days. Three devices were removed, one for severe discomfort two hours after insertion and two at the patients request for later minor symptoms.

The small Dalkon shield and the copper 7 are very effective in many nulliparous uteri. But the former may sometimes need to be fitted under local anaesthesia or intravenous sedation with pethidine and atropine, while and it is now commercially available in Britain (London Rubber Industries). However, exact fitting is essential, as well as proper follow-up if the $25 \mathrm{~S}$ is to be successful on a large scale.

Where systemic medication with the contraceptive steroids is contraindicated, or rejected by the nulliparous patient, or simply not practical, the $25 \mathrm{~S}$ device offers an excellent alternative and simple means of fertility control.-I am, etc.,

London W.1

DESMOND BLUETT

\section{Diabetes Mellitus and Refined Carbohydrate}

SIR,-May we reply to Dr. H. C. Trowell's inquiry (12 May, p. 365)?

Three types of maize meal are common in Rhodesia: straight-run meal containing $2 \mathrm{~g}$ crude fibre/100 $\mathrm{g}$ used by Government institutions and labour contractors, roller meal $(0.8 \mathrm{~g}$ crude fibre $/ 100 \mathrm{~g})$ used in the rural areas, and pearl meal $(0.2 \mathrm{~g}$ crude fibre/100 g) which is preferred by the urban population. We have previously suggested that the amount of crude fibre in maize meal may be less important than its speed of digestion and absorbtion from the alimentary tract. Bread which contains $0.1 \mathrm{~g}$ crude fibre/100 $\mathrm{g}$ is digested by amylase in vitro five times faster than cooked pearl maize meal $(0.2 \mathrm{~g}$ crude fibre/100 g).-We are, etc.,

A. C. B. Wicks

J. J. JONES

University of Rhodesia,

1 Westhuysen, J. van der, Mbizvo, M., and Jones, J. J., Lancet, 1972, 2, 719.
esthuysen,

\section{Incidence of Postoperative Deep Vein} Thrombosis in the Tropics

SIR,-I refer to two articles on postoperative deep vein thrombosis ( 3 March, pp. 515 and 517), the first involving patients in the Sudan by Mr. M. A. Hassan and others, and the second in a Queensland hospital by $\mathrm{Mr}$. O. B. Williams and others.

My own experience in Vietnam in 1968 in a civilian hospital confirms the low incidence of deep vein thrombosis, pulmonary em-

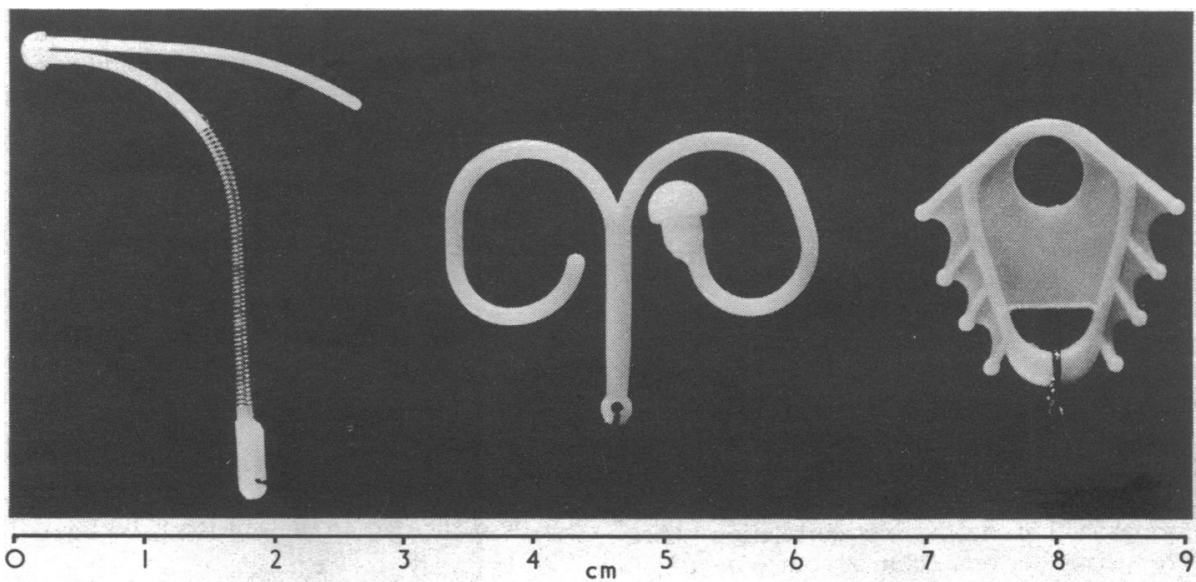

Comparison of Gravigard copper 7 (left), small Dalkon shield (right), and $25 \mathrm{~S}$ device against millimetre scale. 